\title{
DEVELOPMENT OF HIGH CARBON-LOW NICKEL STAINLESS STEEL CONTAINING DIFFERENT MANGANESE CONTENTS
}

\author{
O. A. Hamed ${ }^{*}$, A. R. El- Desouky ${ }^{*}$, A. I. Z. Farahat ${ }^{* *}$, M. S. Hawash ${ }^{*}$ \\ * Department of Mechanical Design and Production Engineering, \\ Faculty of Engineering, Minoufiya University, Egypt \\ ** Central Metallurgical R\&D Institute, CMRDI, Helwan, Egypt.
}

\begin{abstract}
The production of low nickel austenitic stainless steel has increased considerably mainly due to nickel price evolution in the last years. Manganese steels exhibit the best combination of strength and ductility over the whole range of ductile steel grades for car manufacturing. But austenitic stainless steel containing manganese suffers from sigma phase and the material would be subjected to brittle fracture. Carbon decreases the sigma phase formation. However, carbon deteriorates the ductility of austenitic stainless steel. Therefore it was important to study the high temperature deformation of austenitic stainless steel containing manganese with low nickel. This paper is a trial to process austenitic stainless steel with manganese content ranging from 4.35 to 9.27 wt. \%. The high temperature deformation was in range $950{ }^{\circ} \mathrm{C}$ to $1200^{\circ} \mathrm{C}$ to prevent the hot formability with severe cracks. The tensile strength and hardness increase as the $\mathrm{Mn}$ content increases after thermomechanical treatment. The high deformation temperature accelerates the dynamic recrystallization of Fe-Mn steels leading to fine grains. The ferrite phase increases as the Mn contents increases after thermomechanical treatment. Sigma phase after thermomechanical deformation disappears and the final microstructure is fully austenitic with thin carbide on the grain boundaries. At 9 wt. \% Mn content chromium carbide cannot be controlled and deteriorates the strength and ductility.

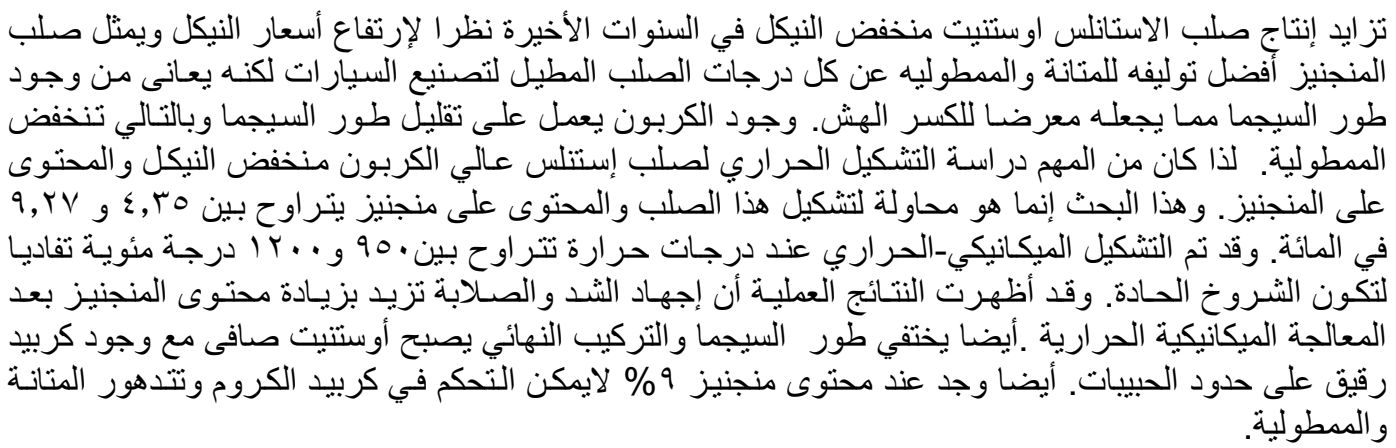

Keywords: Sigma phase; High temperature deformation; Dynamic recrystallization; Thermomechanical treatment (TMT).

\section{INTRODUCTION}

The developed hot rolled microstructure and consequently the final mechanical properties of Low Nickel Stainless Steel are Mn dependent, [1]. Induced martensite decreases the ductility of steel and creates severe crack during plastic deformation such as deep drawing. Ni is responsible for early induced martensite formation at low amount of cold rolling while $\mathrm{Mn}$ is responsible for late induced martensite and consequently the material can be subjected to high amount of cold deformation without induced martensite (i.e. no cracks due to induced martensite). The effect of $\mathrm{Mn}$ on the austenite stability is composition dependent. The austenitic stainless steel containing high manganese suffers from the formation of a $\mathrm{Fe}-\mathrm{Cr}$ intermetallic compound (the brittle and hard constituent corundum i.e. the $\sigma$ ), [2]. Small amounts of nickel and manganese increase the rate of $\sigma$ formation, although large amounts retard $\sigma$ formation, [3]. Carbon additions decrease $\sigma$ formation by forming chromium carbides, thereby reducing the amount of chromium in solid solution, [4]. Additions of vanadium and niobium also promote $\sigma$ formation, [5]. However $\mathrm{Nb}$ is required to prevent or decrease the sensitization phenomenon during high temperature service, [6]. Coarse grain sizes from high solution-annealing temperatures retard $\sigma$ formation, and prior cold working enhances it. The influence of cold work on $\sigma$ formation depends on the amount of cold work and 
its effect on recrystallization [7]. Predominantly out of delta-ferrite, because in stainless steel the composition of the delta-ferrite is similar. At temperatures between 600 and $900^{\circ} \mathrm{C}$ the undesirable phase precipitates in high alloyed steels. Sigma-phase is not only undesirable because of its embrittled effect, but also because of its characteristic to withdraw chromium out of the matrix. The consequence of this is a drastic deterioration of the stability against corrosion. When sigma-phase precipitates out of the delta-ferrite, also austenite is formed through $\mathrm{Cr}$ and Mo decrease (ferrite-forming elements). The arising mixture consists of sigmaphase and austenite, with possible existing residues of delta-ferrite, has evident the character of and eutectic microstructure. Because the sigma-phase goes in solution at temperatures above $900^{\circ} \mathrm{C}$, it can get removed through a corresponding annealing. Nitrogen in the steel reduces the danger of the formation of sigma-phase or suppresses it completely. Characteristic of the sigma-phase is not magnetizable; very brittle bad impact strength, very low corrosion resistance - especially in the direct surroundings through decrease of $\mathrm{Cr}$ and $\mathrm{Mo}$ [8]. Fine grain structure of austenitic stainless steels leads to an increase in the surface density of grain boundary, which provide a dominant supporting action against cavitations .For this reason, fine grain steel samples are characterized by lower damage compared to the medium and coarse grain steel samples [9]. The increase of Mn content can arrest the transformation processing and decrease austenite to ferrite transformation temperature [10].Influence of Mn content and hot deformation on transformation behavior of $\mathrm{C}-\mathrm{Mn}$ steel has been studied. The experimental results showed that deformation in austenitic region accelerated transformation process, and the extension is dependent on the hot deformation and cooling condition. In the present work, the effect of Mn contents through thermomechanical treatment on the mechanical properties, microstructure and wear rate of high Carbon low Nickel stainless steel was investigated.

\section{EXPERIMENTAL PROCEDURE}

\subsection{Materials}

High carbon stainless steel of low nickel content was prepared by casting in the form of Y-blocks. Therefore, a $300 \mathrm{~kg}$ scrap of 304 stainless steel with $\mathrm{Fe}-\mathrm{Mn}$ and $\mathrm{Fe}-\mathrm{Cr}$ master alloys (65 wt. \% Fe, 35\% \% $\mathrm{Mn}$ or $\mathrm{Cr}$ ) were melted together using an open air induction furnace, with capacity of $350 \mathrm{~kg}$, and frequency of $1000 \mathrm{~Hz}$. The melting temperature was $1650^{\circ} \mathrm{C}$ while the pouring temperature was $1625^{\circ} \mathrm{C}$. The chemical composition of Y-blocks is listed in Table1. Three different melts with variable $\mathrm{Mn}$ and C-content were prepared. The Y-blocks were machined and prepared for hot forging to remove the sand layer.

Table 1, Alloys chemical compositions, Wt \%.

\begin{tabular}{|c|c|c|c|}
\hline Alloy No. & 1 & 2 & 3 \\
\hline $\mathrm{C}$ & 1.06 & 1.32 & 1.24 \\
\hline $\mathrm{Si}$ & 0.43 & 0.578 & 0.697 \\
\hline $\mathrm{Mn}$ & 4.35 & 6.48 & 9.27 \\
\hline $\mathrm{P}$ & 0.04 & 0.027 & 0.0574 \\
\hline $\mathrm{S}$ & 0.00753 & 0.00498 & 0.00224 \\
\hline $\mathrm{Cr}$ & 14.49 & 15.01 & 14.86 \\
\hline $\mathrm{Mo}$ & 0.184 & 0.155 & 0.134 \\
\hline $\mathrm{Ni}$ & 5.02 & 4.73 & 4.96 \\
\hline $\mathrm{Cu}$ & 0.212 & 0.458 & 0.201 \\
\hline $\mathrm{Nb}$ & 0.433 & 0.649 & 0.571 \\
\hline $\mathrm{V}$ & 0.061 & 0.067 & 0.079 \\
\hline
\end{tabular}

\subsection{Thermomechanical Processing}

The manufacturing process of hot rolled high manganese steel without any cracks may include the following steps:

1- Preparing the Fe-Mn steel ingots or slabs. The steel can be alloyed with one or more elements.

2- Heating the ingot at a temperature ranging from 1000 up to $1300^{\circ} \mathrm{C}$ for $12-40$ hours to homogenize the ingot.

3- Solid solution treatment at a temperature ranging from 1000 up to $1300^{\circ} \mathrm{C}$ for $30-60$ minutes followed by hot rolling. Treatment at higher a temperature more than $1100^{\circ} \mathrm{C}$ results in coarsened grains which deteriorates the strength. If the temperature is lower than $900^{\circ} \mathrm{C}$, the hot rolling will be so difficult.

4- Hot rolling up to a total reduction ratio of $40 \%$ with a strain rate less than $2.0 \mathrm{sec}^{-1}$ and reduction ratio less than $7 \%$ per pass

During the hot deformation, Fe-Mn steel should be either heated under a non-oxidizing atmosphere or coated to avoid surface oxide scales and depletion of the alloying elements, [11]. Before hot forging, the materials were subjected to homogenization process for 9 hours to dissolve all segregated elements [12]. After homogenization the materials were hot forged at $1200^{\circ} \mathrm{C}$, 9hr as shown in Fig. 1 with $90 \%$ crosssection reduction then solution treated at $1200^{\circ} \mathrm{C}$ for $1 \mathrm{hr}$ and finally water quenched.

\subsection{Hardness and Tensile Testing}

Hardness and tensile tests were carried out at room temperature for as cast and hot forged materials according to ASTM standards E 140 for hardness using United Hardness Tester and for tensile A 370 using Shimadzu $50 \mathrm{kN}$ universal testing machine, respectively. The strain rate $\left(1.7 * 10^{-5} \mathrm{sec}^{-1}\right)$ was calculated according to the cross head speed of 0.05 $\mathrm{mm} / \mathrm{min}$ and gauge length of $50 \mathrm{~mm}$.

\subsection{Microstructure and $X$-Ray Investigations}


For both as-cast and as-forged materials polished cross section of the samples were prepared in order to investigate the microstructure using an optical microscope from Olympus equipped with MARS software as well as for scanning microscopy (JOEL (JSM-T300)). X-ray analysis (EDX) was performed in order to obtain the phases in as-cast and as-forged samples. Phase formation were examined using a Siemens diffractometer (D-500) with monochromatic $\mathrm{Cu} \mathrm{K} \alpha$ radiation in the angular range of $2 \theta=30-70^{\circ}$ at step rates of $0.01 \% \mathrm{sec}$. The materials after thermomechanical processing were investigated using X-ray detection to identify the different phases after hot forging and solution treatment.

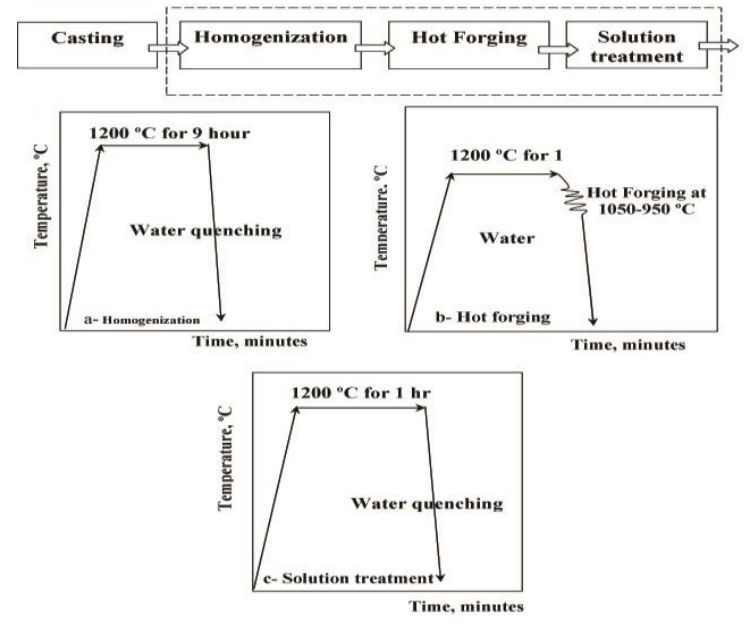

Fig. 1 Thermomechanical treatment procedure

\subsection{Dry Sliding Wear Test}

Dry sliding wear test was carried out at room temperature. Experimental design technique was used to verify the influence of linear velocity and applied stress on the wear rate of the alloy. As a first step in the experimental design technique, the lower and upper levels of each parameter were accurately predetermined as listed in Table 2. A pin-on-disc machine was used at a load varying from 0.5 to $10 \mathrm{~kg}$. The counter face was made from high speed steel (HSS) with diameter $200 \mathrm{~mm}$ and hardness 1000HV.Pin height losses were automatically measured at different distance intervals. This test at a given sliding velocity and load was repeated three times with identical new samples on fresh disk surface. The surface and debris of the samples were examined using scanning electron microscope.

Table 2, Parameter levels of the wear test

\begin{tabular}{|c|c|c|}
\hline Parameter & $\mathrm{V}(\mathrm{m} / \mathrm{sec})$ & $\mathrm{P}(\mathrm{MPa})$ \\
\hline Upper & 12.723 & 2.131 \\
\hline Lower & 4.18 & 0.795 \\
\hline
\end{tabular}

\section{RESULTS and DISCUSSION}

\subsection{As-cast Structure}

Fig. 2 shows the optical microstructure of the cast alloys. The as-cast structure of the Y-blocks exhibits mainly austenitic phase with different volume fraction of sigma phase shown as separated islands as shown in Fig. 2. Mn seems to have no noticeable effect on the as-cast microstructure of the investigated alloys.

\subsection{Hot forged structure}

Several experimental trials recommended that the high temperature deformation should be in range between $900^{\circ} \mathrm{C}$ and $1200^{\circ} \mathrm{C}$ otherwise the material will suffer from severe cracks, [13]. The microstructure after thermomechanical treatment shows fine grains as detected in Fig.3.The higher deformation temperature, the finer are the recentralized grains. Sigma phase after thermomechanical deformation disappears and the final microstructure is fully austenitic with thin carbide at grain boundaries. The severe hot deformation highly refines the austenite grain size of Fe-Mn steels. The high deformation temperature accelerates the dynamic recrystallization of Fe-Mn steels resulting in fine structure as shown in Fig. 3 On the other hand, the increase of Mn content increases the deformation resistance [14]. The activation energy for hot deformation was increased with increasing $\mathrm{Mn}$ content, and dynamic recrystallization was observed for all alloys. However, Mn was found to delay dynamic recrystallization. An increase in Mn content resulted in an increase in stress and the corresponding strain thus revealing the pronounced influence of $\mathrm{Mn}$ on the hot deformation process. It was found that increasing the Mn content increases the ferrite in the matrix of austenite. At low Mn concentrations (less than 2 wt. $\%$, Mn behaves as an austenite stabilising element, whereas at high concentrations $\mathrm{Mn}$ behaves as a ferrite stabilising element. As Mn content increases from 4 to 9 wt. $\%$, the ferrite volume fraction increases from 13 to $25 \%$. Furthermore, the existence of $\mathrm{Cr}(\sim 15 \mathrm{wt} . \%)$ in the investigated alloys not only improves the hot workability, prevents crack formation and surface oxidation during thermomechanical processing, but also retards the austenite to ferrite transformation, thus making it easier to retain $\gamma$ at room temperature.

It may be noted that the investigated steel was forged in the non-recrystallized austenite region, with high densities of substructure as dislocation formed in austenite, which increased the nucleation sites of ferrite and promoted ferrite transformation. This explains the increase of ferrite with Mn-content. Furthermore, the finer ferrite grains within $\gamma$ grains observed in Fig. 2 at high deformation temperature $\left(1200^{\circ} \mathrm{C}\right)$ are attributed as follows; It is known that the increase of Mn Can suppress ferrite nucleation at $\gamma$ grain boundaries and restrain the growth of ferrite 
resulting from a solute drag effect of $\mathrm{Mn}$ on phase boundary, which can contributes to forming finer ferrite grains.

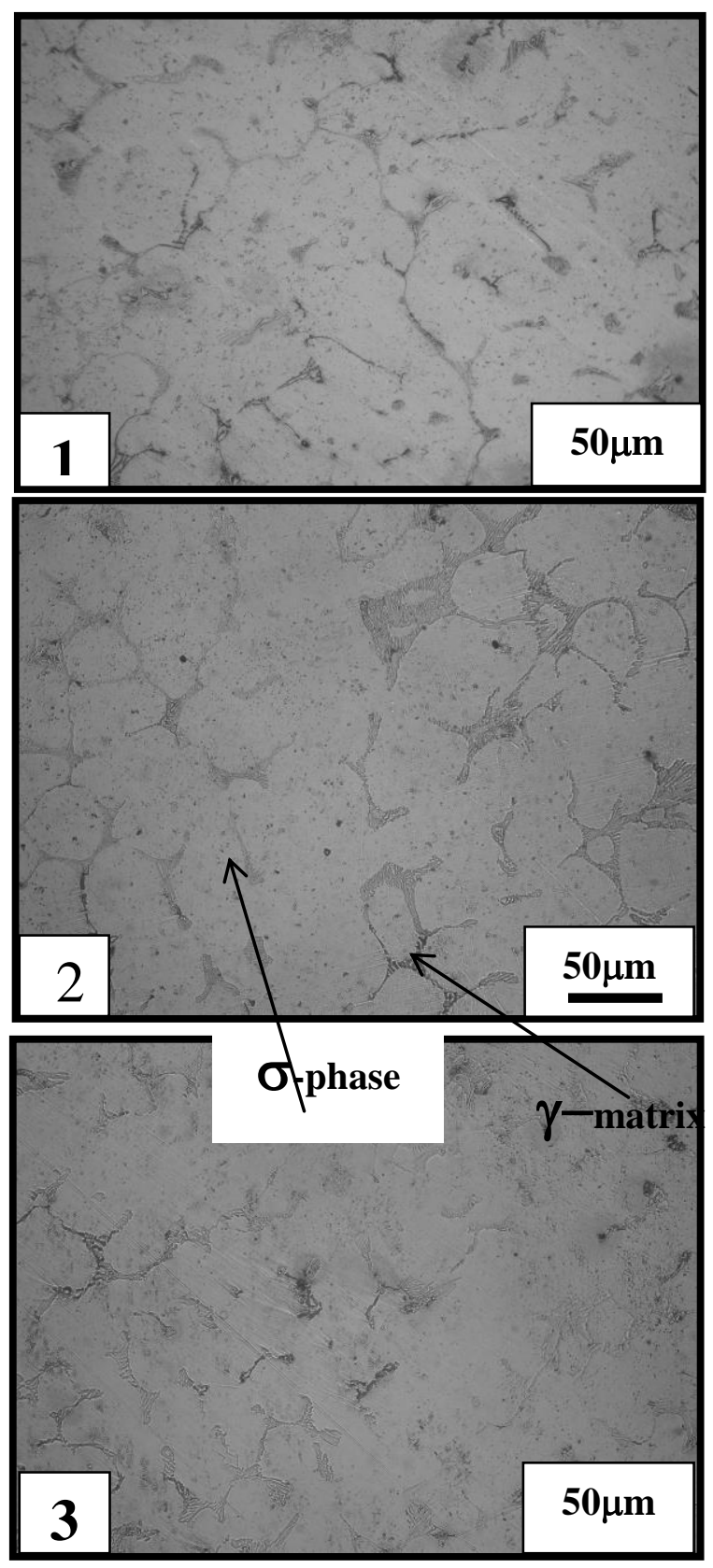

Fig. 2 The as-cast microstructure for different alloys

\subsection{Hardness and Tensile Test Results}

The mechanical properties of the materials after casting and thermomechanical treatment were investigated and the results are plotted in Figs. 4 and 5. It is found that the hardness increases with increasing the manganese content. For alloy 3, the hardness relatively decreases due to increasing the amount of ferrite, Fig. 4. The high levels of hardness for the as forged compared with the as-cast materials can be attributed to a group of interacting mechanisms: strain-induced temperature of $\gamma$ to $\alpha$ or $\zeta$ martensite, fine mechanical twinning, staking fault dislocation interaction and carbon atoms dislocation interaction.

The tensile strength increases with Mn content up to 6.48. \%. However, alloy 3 shows a slight decrease in the strength after TMT. At 9 wt. \% Mn content chromium carbide cannot be controlled and deteriorates the strength and ductility. Fig. 6 shows the effect of manganese content on the ductility after thermomechanical treatment. It is clear that the ductility increases slightly with increasing $\mathrm{Mn}$ content. However for 9.27 wt. \% Mn alloy, the ductility decreases due to chromium carbides formation as shown in Fig. 7.
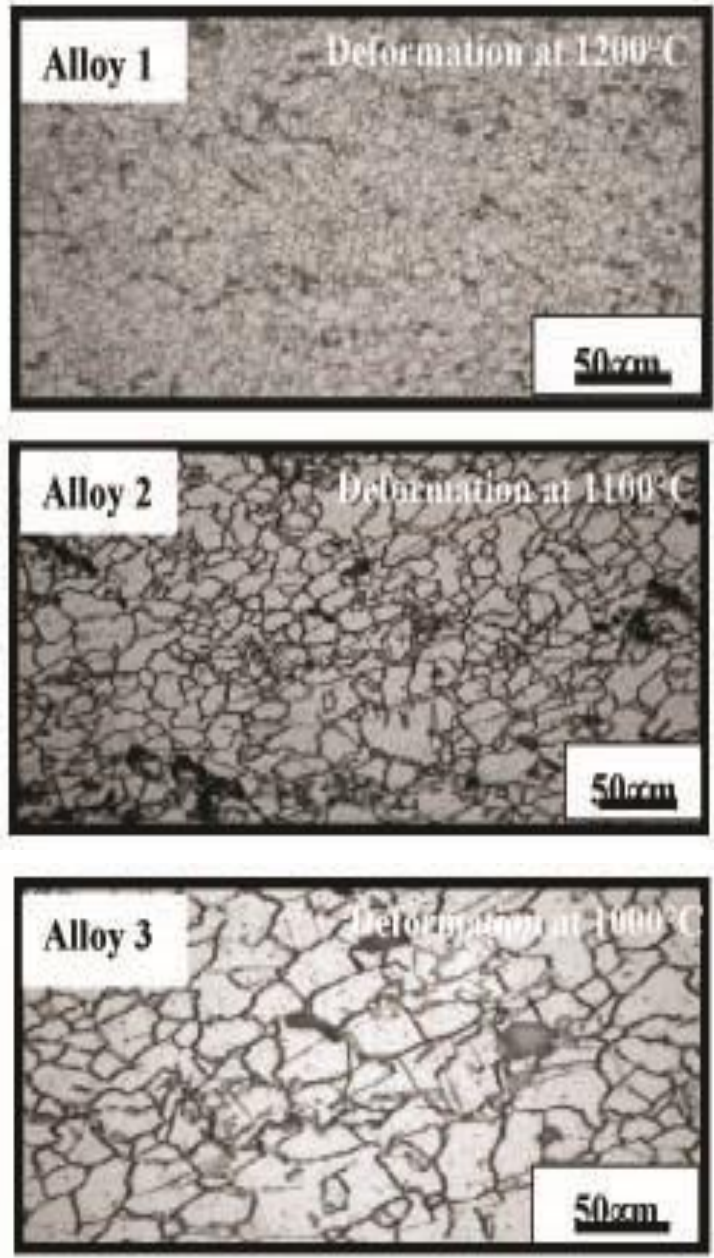

Fig. 3 Hot forged microstructure and solution treated for different alloys

\subsection{X-Ray Investigation of Fe-Mn Steel}

The volume fractions of austenite and ferrite stabilizer are determined by the Direct Comparison Method, Fig .8. It is found that increasing the manganese content raises the ferrite volume fraction Fig. 9. The effect of deformation on ferrite transformation becomes more obvious with the increase of $\mathrm{Mn}$ content. The addition of $\mathrm{Mn}$ can increase the distortion in austenite during 
deformation, thus promoting the accumulation of deformation energy in austenite.

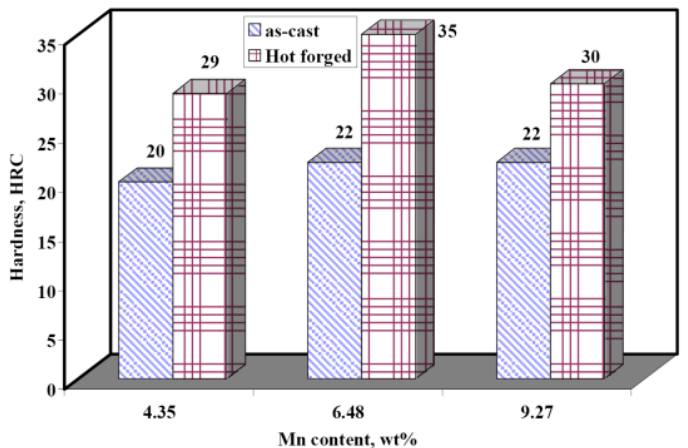

Fig. 4 Hardness values for different alloys before and after thermomechanical treatment

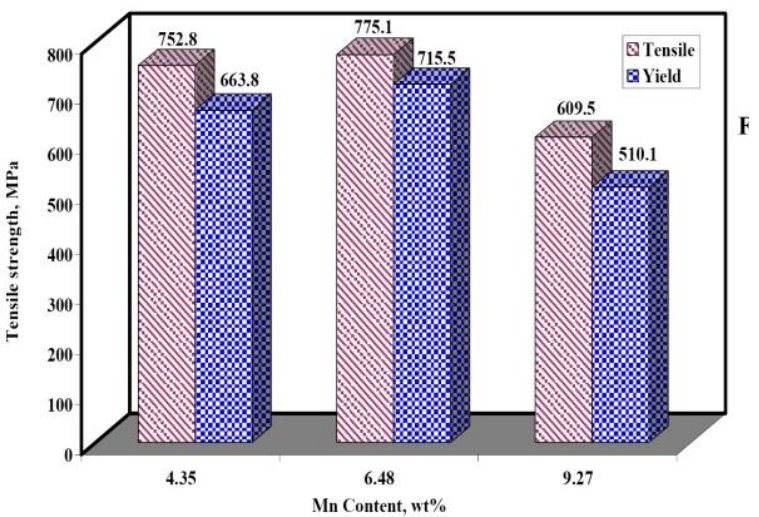

Fig. 5 Tensile strength for different alloys after thermomechanical treatment

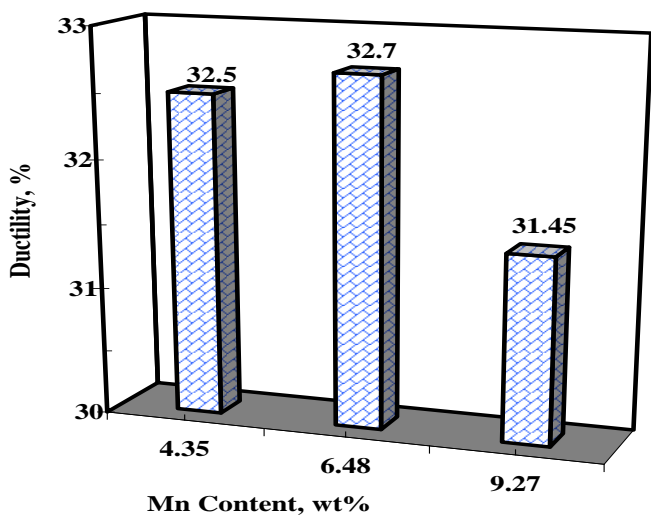

Fig. 6 Alloys ductility at different Mn contents

\subsection{Wear Results}

\subsubsection{The as cast condition}

Figure 10 shows the relation between sliding velocity $(\mathrm{m} / \mathrm{s})$, Pressure $(\mathrm{MPa})$ and wear rate $(\mu / \mathrm{min})$. The experimental results can be represented by the following equation:

Wear rate $(\mathrm{micron} / \mathrm{min})=\mathrm{a} * \exp -0.5 *\left(\left(\mathrm{x}-\mathrm{x}_{0}\right) / \mathrm{b}\right)^{2}$

At low level of pressure $(0.790 \mathrm{Mpa})$, wear rate is slightly affected by velocity up to $8 \mathrm{~m} / \mathrm{sec}$ beyond which wear rate increases dramatically. However, at high level of pressure, the wear rate remains almost constant up to $10 \mathrm{~m} / \mathrm{sec}$ followed by rapid increase in wear rate with sliding velocity. The effect of pressure on wear rate seems to depend on sliding velocity. At low level of velocity $(4 \mathrm{~m} / \mathrm{sec})$ wear rate is unaffected by pressure. However, at the high level of velocity $(14 \mathrm{~m} / \mathrm{sec})$, wear rate increases with pressure reaches maximum followed by a decrees. As shown in Fig.11 at low level of velocity wear rate is low and the worn surface appears irregular while at high level of velocity wear rate is high. With regular lines appear on the worn surface which looks like fish scales.
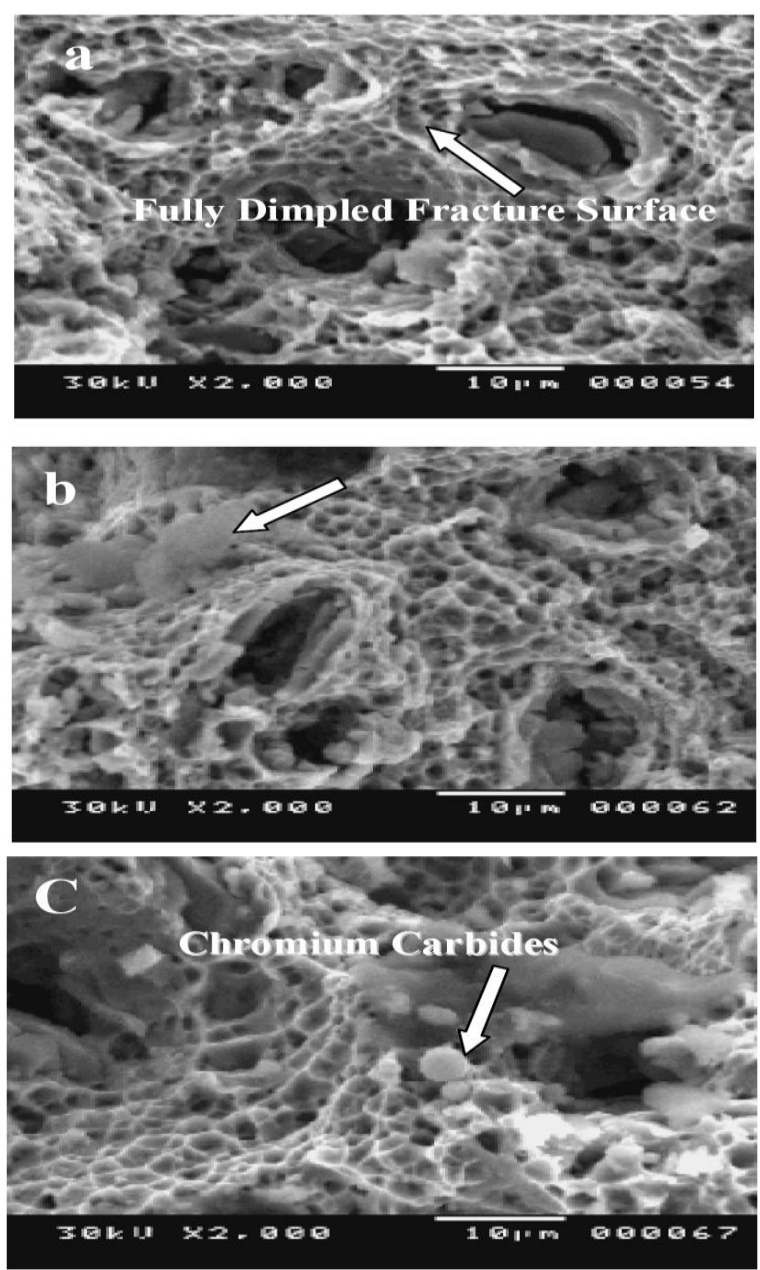

Fig.7 Fracture surfaces of tensile specimen after thermomechanical treatment

The initial lower wear rate (with velocity) may be due to the lower contact area at a given load resulting from its higher level of hardens. Thus, wear in this stage occurs by the removal of initial oxide layers and surface contaminants. Also in this stage (run in), the oxidation of surfaces begins and progresses with frictional heating generated during sliding. The transfer layer evolves tow the second stage characterized by high wear rate (at velocity up to $8 \mathrm{~m} / \mathrm{see}$ ). The extent of which is determined by 
conditions of the load, sliding velocity and environmental condition. The high wear rate associated with high sliding velocity, is characterized by real area of contact, the speared of oxide and compacted transfer layer as well as the evaluation of meting surface to better conformity Fig.11a.

\subsubsection{The as forged condition}

Figure 12 shows the relation between sliding velocity $(\mathrm{m} / \mathrm{s})$, Pressure $(\mathrm{MPa})$ and wear rate $(\mu / \mathrm{min})$.

The experimental result could be represented by the following equation:

\section{$\mathrm{f}=\mathrm{a} * \exp \left(-0.5 *\left(\left(\left(\mathrm{x}-\mathrm{x}_{0}\right) / \mathrm{b}\right)^{2}+\left(\left(\mathrm{y}-\mathrm{y}_{0}\right) / \mathrm{c}\right)^{2}\right)\right)$}

At low level of pressure wear rate remains unaffected by velocity up to $(8 \mathrm{~m} / \mathrm{sec})$ beyond which there is a raped increase in wear rate. However, at high level of pressure the wear rate is unaffected by velocity. As in fig. 13 at low level of velocity wear rate is low and the worn surface appears irregular while at high level of velocity wear rate is high, regular lines appear on the worn surface which looks like fish scales.

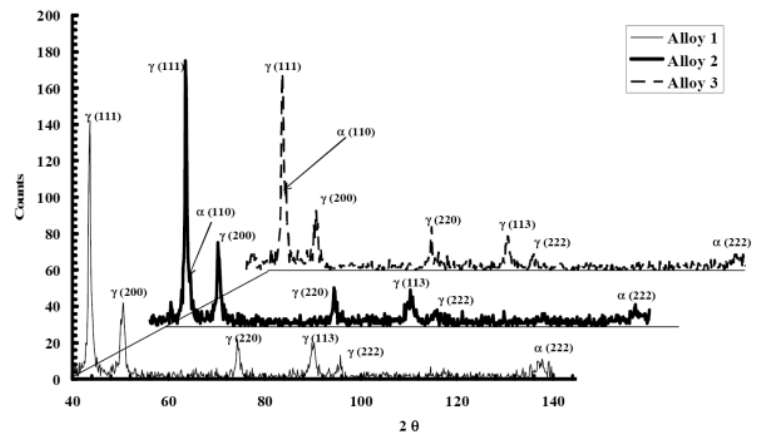

Fig. 8 X-ray diffraction patterns of austenite and ferrite for different alloys after thermomechanical treatment

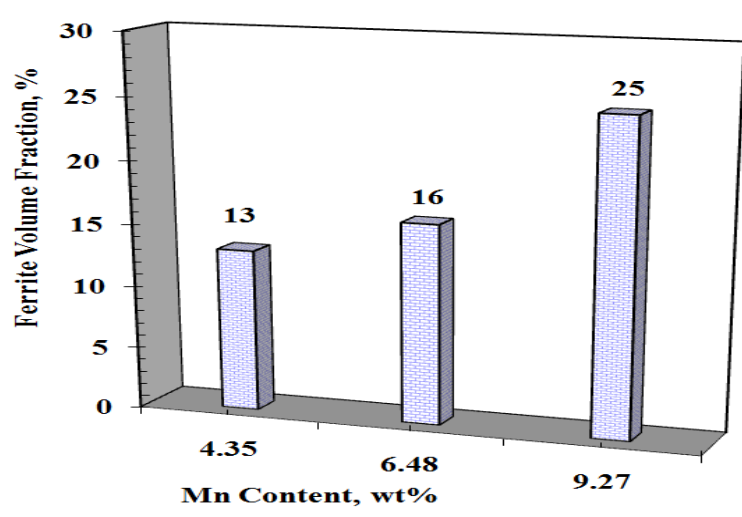

Fig. 9 Effect of Mn content on ferrite volume fraction

\subsubsection{Wear characteristics}

A hand of the wear test results presented in the previous parts, the following points have to be highlighted: For both the as-cast and as-forged steels have similar wear behaviour: the first linear segment (run-in) is found to be steeper compared with the second linear segment (steady state). The transitions occur at various time intervals depending on the investigated structures as well as wear test parameters. Others researches have observed similar tends in wear of stainless steel. The SEM micrographs of the worn surfaces of the as cast and as forged steel show a highly compacted transfer layer of oxides at many places of surfaces. The three types of oxides of iron $\left(\mathrm{Fe}_{2} \mathrm{O}_{3}, \mathrm{Fe}_{3} \mathrm{O}_{4}\right.$, and $\left.\mathrm{FeO}\right), \alpha$ $\mathrm{Fe} 2$ has been reported to be a low temperature oxide, which forms around temperature less than $450^{\circ} \mathrm{C}$.

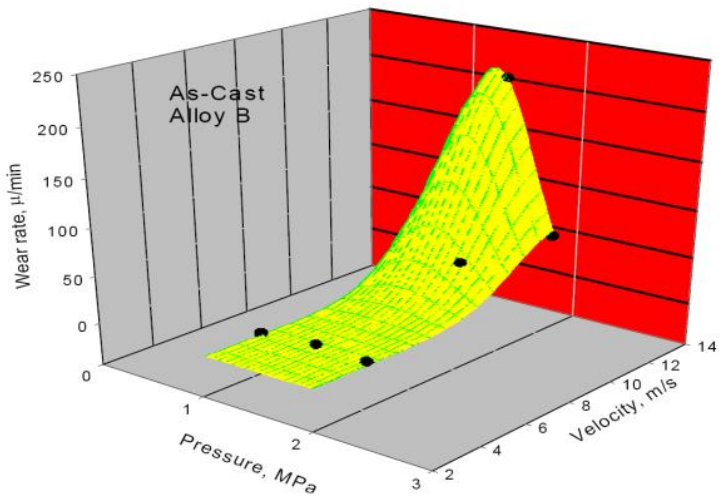

Fig.10 Relation between sliding velocity $(\mathrm{m} / \mathrm{s})$, pressure $(\mathrm{MPa})$ and wear rate $(\mu / \mathrm{min})$

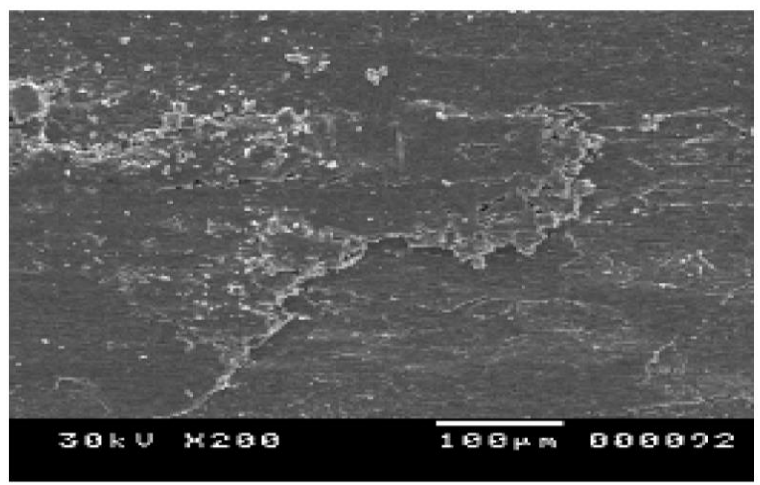

SEM of worn surface for the as cast samples at: $4 \mathrm{~m} \backslash \mathrm{sec}$

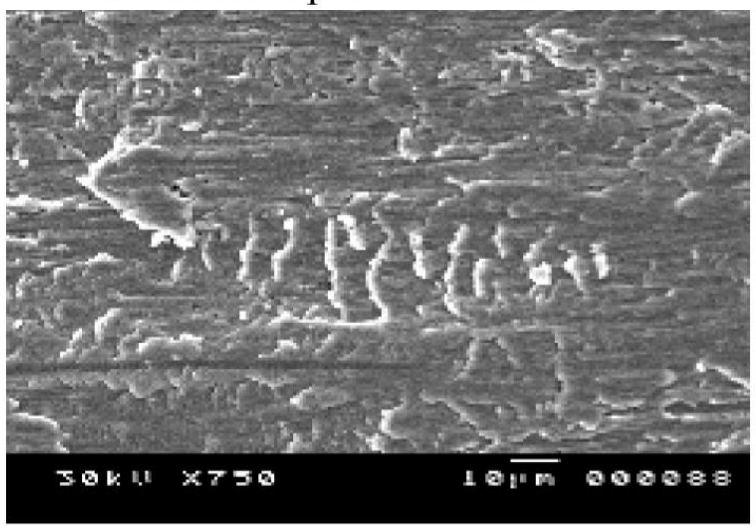

SEM of worn surface for the as cast samples at: $12 \mathrm{~m} \backslash \mathrm{sec}$

Fig. 11 SEM of worn surface at different velocity

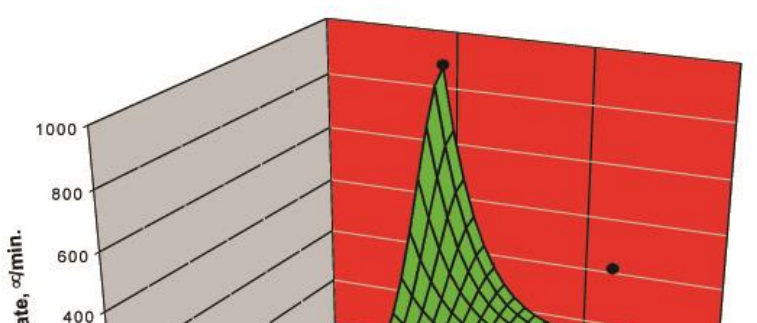


Fig.12 The relation between sliding velocity $(\mathrm{m} / \mathrm{s})$, pressure $(\mathrm{MPa})$ and wear rate $(\mu / \mathrm{min})$

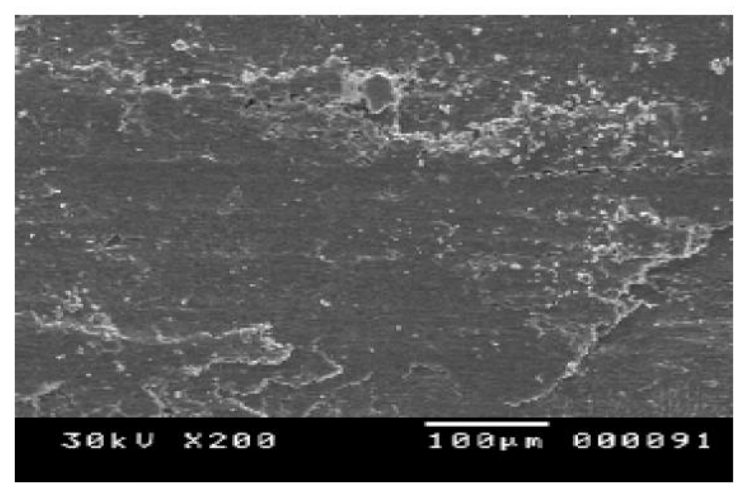

SEM of worn surface for the as forged samples at: $4 \mathrm{~m} / \mathrm{sec}$

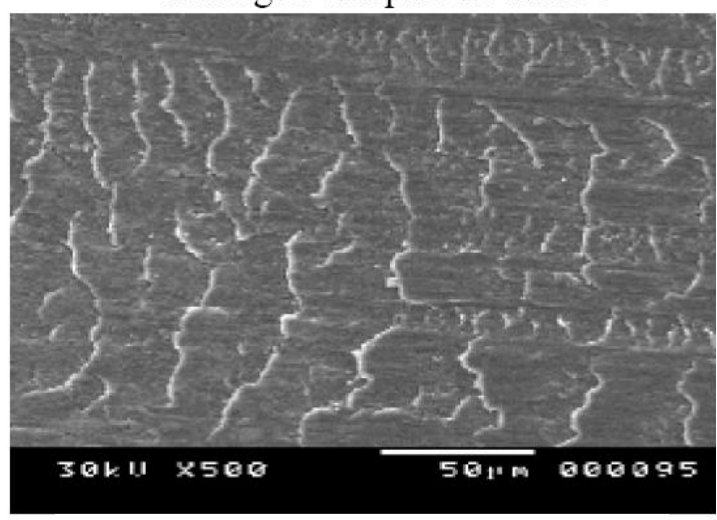

SEM of worn surface for the as forged samples at: $12 \mathrm{~m} / \mathrm{sec}$

Fig. 13 SEM of worn surfaces at different velocities

In the present study, no change was observed in the nature of the formed oxide, possibly because the sliding temperature in any of loads did not overweigh the formation temperature of $\mathrm{Fe}_{2} \mathrm{O}_{3}$. The run-in stage, in most of the examined samples, give rise to a higher wear rate as compared to that in the steal state.
This can be explained on the basis of initial surface roughness of the wearing materials.

When two previously unworn surfaces are first brought into contact with and slide relative to one another, mechanical, thermal, chemical, and microstructural Changes begin to occur in and adjacent to the contact at asperities. So, the surfaces evolve to attain better conformity to each offer at the end of the run-in stage. The wear in this stage occurs by the removal of high asperities, initial oxide layers, and surface contaminants. Consequently, the material loss and the wear rate are higher in the run-in stage of wear. In the run-in stage, the oxidation of the surfaces begins and progresses with frictional heat generated during sliding. The transfer layer of the oxide may, thus begin to form in the run-in stage and evolves to the steady state, providing an extent of cover determined by the condition of the load, sliding velocity, and material characteristics.

The second stage of wear indicates a steady-state with respect to:

1- The evaluation of malting surface to better conformity,

2- The spread of oxide and compacted transfer layer,

3- The real area of contact Such transfer layer protects the underlying metal and the ear rate decreases.

It has been found that the as-forged specimen are able to hold a thicker transfer layer of oxide move firmly compared to the as -cast ones.

\section{CONCLUSIONS}

Thermomechanical processing of a new family of stinaless steel that contains c-content $(\sim 1.3 \%)$ as high Mn-content ( 9\%) was performed. The target was to develop austentic Mn- steel that combine a moderate strength with high ductilty and to fully or partially replace $\mathrm{Ni}$ in austentie stainless steel in periods of $\mathrm{Ni}$ shortage. The following conditions were observed at:

1- The high temperature deformation should be in the range between $950^{\circ} \mathrm{C} 1200^{\circ} \mathrm{C}$ otherwise the material will suffer from severe cracks.

2- The high deformation temperature accelerates the dynamic recrystallization of $\mathrm{Fe}-\mathrm{Mn}$ steels resulting in fine grains that have position impacts on strength properties.

3- The materials tensile strength and hardness increase as the Mn-contents increases after thermomechanical treatment up to $6.48 \%$.

4- The ferrite phase increases as the $\mathrm{Mn}$ contents increases after thermomechanical treatment.

5- Sigma phase after thermomechanical deformation disappears and the final microstructure is fully austenitic with thin carbide on the grain boundaries. 
6- At 9 wt. \% Mn content, chromium carbide cannot be controlled and deteriorates the strength and ductility.

7- For a given load, the wear of both as-cast and asforged steel pins increases with sliding time under dry sliding. However, the wear loss - time relationship can be represented by two: run -in and steady-state segments.

8- It has been found that the as forged specimens are able to hold a thicker transfer layer of oxide more firmly compared to the as cast ones. The wear rate in both segments are higher for as-cast than those for the forged, which may be attributed to the relatively higher hardness, homogeneity of structure as well as the grain refinement of the forged samples.

\section{REFERENCES}

[1] P. Rama Rao and V.V. Kutumbarao, "Developments in Austenitic Steels Containing Manganese", International Materials Review, Vol. 34, No. 2, 2007.

[2] I. Kim et al., "United States Patent", Patent Number: 431753, July 11, 1995.

[3] M. Chesseret et al., "United States Patent", Patent Number: 6056917, May 2, 2000.

[4] J. E. Bayraktar, F. A. Khalid, C. Levaillant, "Deformation and Fracture Behavior of High manganese Austenitic Steel", Journal of Materials Processing Technology, 147, pp. 145154, 2004.

[5] T. EL-Bitar and E. EL-Banna, "Improvement of Austenitic Hadfield Mn-Steel Properties by Thermomechanical Processing", Canadian Metallurgical Quarterly, pp. 361-368, 2000.
[6] I .Kim et al., "United States Patent", Patent Number: 5647922, July 15, 1997.

[7] N. Cabanas, N. Akduc, J. Penning, and B.C. De Cooman, "High-Temperature Deformation Properties of Austenitic Fe-Mn Alloys", Metallurgical and Materials Transactions A, Vol. 37A, Nov. 2008.

[8] J. Pardal et al, 'Deformation Induced Martensitic Transformation in a 201 modified austenitic stainless Steel”, University Federal, pp. 455760, February 2009.

[9] G. bregliozzi. et al., "Cavitation Wear behaviour of austenitic stainless steels with different grain sizes", University of Perugia, 8 October 2004.

[10] W. Jing et al, "Influence of Mn content and hot deformation on transformation behavior of CMn steels", Journal of iron and steel research, 15, No. 2, pp. 51-55, 2008.

[11] P. Cugy, A. Hildenbrand, M. Bouzekri, D. cornette, S. Goklu, H. Hofmann, “A super high strength Fe-Mn-C austenitic steel with excellent formability for Automobiler Applications", www.msm.cam.ac.uk/phasetrans/2005/LINK/92.pdf

[12] Y. Tomota, M. Strum and J.W. Morris, "Microstructural dependence of Fe-high Mn tensile behavior", Metallurgical Transaction A, Vol.17A, March 1986.

[13] J. Choi et al., "United States Patent", Patent Number: 5634990, June 03, 1997.

[14] N. Cabanas, et al., "High temperature deformation properties of austenitic Fe-Mn alloys", Metallurgical and materials transactions, Volume 37A, Nov. 2006. 